\title{
KARL HEINRICH RAU Y EL DIAGRAMA MARSHALLIANO DE LA OFERTA Y LA DEMANDA *
}

\author{
ANDRÉS VÁZQUEZ PÉREZ \\ Departamento de Economía \\ Consejo Superior de Investigaciones Científicas, Madrid
}

\section{RESUMEN}

Este trabajo muestra que el economista alemán Karl Heinrich Rau (1792-1870) merece ser justamente considerado como precursor del conocido diagrama marshalliano de la oferta y la demanda, o diagrama de las tijeras de Marshall. Marshall conoció la obra de Rau desde la temprana edad de su formación como economista, pero se refirió a él de forma incompleta y fuera de contexto, silenciando su pionera descripción gráfica del equilibrio competitivo. El artículo concluye poniendo de manifiesto que la conocida acusación schumpeteriana acerca de la falta de generosidad de Marshall con todos aquellos cuyos trabajos están íntimamente relacionados con el suyo se aplica igualmente al caso de Rau.

\section{ABSTRACT}

This paper shows that the German economist Karl Heinrich Rau (1792-1870) deserves to be credited as precursor of the marshallian well-known diagram of the supply and demand, or Marshall's scissors diagram. Marshall

N. de E.: Fecha de recepción del artículo en la Revista de Historia Económica: noviembre, 2000.

Fecha de aprobación por el Consejo de Redacción: noviembre, 2001.

* A la memoria de mi tío-abuelo Manuel Fernández Nuevo (1872-1957), campesino leonés, emigrante y, sobre todo, hombre bueno y ejemplar. Este trabajo ha sido financiado por el Ministerio de Educación y Cultura (DGICYT, PB 97-1133). El autor expresa su agradecimiento a Manuel Francisco Pérez López, Investigador del Instituto de Filosofía del CSIC, por la traducción al castellano de los párrafos en alemán citados en el texto, y a los evaluadores anónimos de esta Revista, por sus valiosas sugerencias. 
was aware of Rau's work at an early stage in his economic studies, but he referred to him in an incomplete way and not where he should, silencing his pioneering graphic description of competitive equilibrium. The paper concludes by asserting that the well-known schumpeteriam claim on Marshall's lack of generosity with all those whose work was closely related to his own applies likewise to the case of Rau.

En la historia del pensamiento económico, Alfred Marshall (1842-1924) sigue siendo un autor controvertido. Entre los que creen, como su discípulo Frank Lavington, que «todo está en Marshall, si uno se toma la molestia de hacerlo aflorar» ${ }^{1}$, y los que consideran, como el Premio Nobel George J. Stigler, que «Marshall, con su elevado prestigio, retrasó el advenimiento de la edad del formalismo abstracto de la tradición Lausanniana durante una generación al menos, y, con la ayuda de su principal alumno, Keynes, posiblemente durante más de dos» ${ }^{2}$, las opiniones acerca de su generosidad y originalidad científica son muy diversas. En su conocido ensayo biográfico sobre este autor, su distinguido alumno John Maynard Keynes escribió: «Los ensayos matemáticos y diagramáticos de Teoría Económica de Marshall fueron de tal índole en cuanto a su garra, alcance y rigurosidad científica, y fueron tanto más allá de las "brillantes ideas" de sus predecesores, que podemos proclamarle justamente como el fundador de la moderna economía diagramática» ${ }^{3}$. En el mismo sentido, Parkin, y Parkin y King han escrito más recientemente que entre los primeros tratamientos gráficos de la oferta y la demanda «sólo el de Marshall es lo suficientemente moderno como para ser reconocido por los lectores de los actuales libros de texto» ${ }^{4}$.

Contrariamente, para Mirowski, «Marshall no merece ser considerado ni como descubridor de nada ni como teórico original de ningún género, [...] por encima de todo fue un escritor de libros de texto, un divulgador y sintetizador de doctrinas contradictorias» ${ }^{5}$. Y Joseph Schumpeter, en su monumental Historia del Análisis Económico, reconoce que «Marshall es menos que generoso con todos aquellos cuyas aportaciones están ínti-

${ }^{1}$ Citado por Wright (1927, p. 504).

${ }^{2}$ Stigler (1990, p. 12).

${ }^{3}$ Keynes ([1925] 1966, p. 24; comillas en el original).

${ }^{4}$ Parkin (1990, pp. 84-85) y Parkin y King (1995, pp. 88-89). Sin embargo, ni Dupuit fue el primero que dibujó una curva de demanda, ni Jenkin el primero que representó conjuntamente las curvas de demanda y oferta, como sostienen estos autores.

${ }^{5}$ Mirowski (1990, p. 83). 
mamente relacionadas con la suya», y le acusa de «haber formulado afirmaciones inadecuadas de prioridad». Y, en una nota a pie de página, añade: «Reiteradamente me ha impresionado el hecho de que economistas competentes y hasta eminentes tengan la acrítica costumbre de atribuir a Marshall cosas que, en sentido "objetivo", se deben atribuir a otros (ihasta la curva "marshalliana" de la demanda!)». Para Schumpeter, las curvas de demanda y de oferta, así como la teoría estática del monopolio, son del célebre economista francés Antoine Augustin Cournot, pero Marshall, dice, «no reconoce el mérito a Cournot más que de un modo general, y no le cita donde habríamos podido esperar una cita precisa». Y lo mismo ocurre, añade Schumpeter, «en los casos, menos importantes, de Dupuit y Fleeming Jenkin, a los que sólo alude en una nota a pie de página situada, además, fuera de lugar» 6 .

El propósito de este trabajo es poner de manifiesto que el economista alemán Karl Heinrich Rau (1792-1870) merece ser legitimamente considerado también como precursor del denominado diagrama marshalliano de la oferta y la demanda, o diagrama de las tijeras de Marshall. En 1841, tres años después de la publicación de las famosas Recberches sur les principes matbématiques de la théorie des richesses de Cournot, y con anterioridad a Dupuit, Mangoldt y Jenkin, mencionados habitualmente como precursores de la geometría marshalliana ${ }^{7}$, Rau utilizó un diagrama similar al de Marshall para describir la formación del precio de equilibrio competitivo. Y fue Rau, y no Marshall, como se afirma generalmente en la literatura económica, quien introdujo la práctica ahora habitual entre los economistas,

- Schumpeter (1971, pp. 918-919; cursivas y comillas en el original).

7 Para detalles y referencias, véase, por ejemplo, Humphrey (1992). Sobre Fleeming Jenkin, véase también Rodríguez Braun (1995). En cuanto a Mangoldt, quizá es inmerecido el conocido elogio de Edgeworth (1894, p. 630) cuando afirma que «Mangoldt, que escribe sin referencia a sus predecesores, Cournot, Dupuit, y Gossen, puede reivindicar ser uno de los descubridores independientes de la teoría matemática de la Demanda y la Oferta». Al margen de que su análisis gráfico está claramente inspirado en el de Rau, como el propio Mangoldt reconoce, Marshall difícilmente pudo haberlo conocido, ya que, según Groenewegen (1995, pp. 153-154), la única edición que poseyó de la obra de Mangoldt fue la publicada después de su muerte, en 1871, por Friedrich Kleinwächter, quien suprimió todo el análisis geométrico de la obra arguyendo que «le era totalmente inconcebible que los gráficos o las fórmulas matemáticas pudiesen facilitar la comprensión de las leyes económicas». Por otra parte, es igualmente cuestionable la afirmación de Hennings (1980, p. 670, n. 33) de que Mangoldt no conoció la obra de Cournot, pues autores mencionados por él en su obra, como Rau y Roscher, citan las Recherches. Finalmente, es significativo que Mangoldt (1863, p. 49), como Cournot (1969, pp. 68-69) antes que él, haya considerado también el caso excepcional conocido actualmente como efecto Veblen o consumo conspicuo, en el que a consecuencia de la vanidad o el lujo, la demanda no disminuye, sino que aumenta, al elevarse el precio. 
contraria a la convención matemática, de representar la variable independiente (precios) en el eje de ordenadas y la dependiente (cantidades) en el eje de abscisas. Marshall citó a Rau en las dos primeras ediciones de los Principios, pero también en este caso lo hizo de forma incompleta y fuera de contexto, silenciando, en cambio, su precursora descripción gráfica del equilibrio competitivo, aun cuando hay evidencia de que Marshall conocía las curvas de oferta y demanda de Rau desde la temprana época de su formación como economista.

Graduado en la Universidad de Erlangen, Rau fue nombrado profesor de esta universidad en 1816, y de la de Heidelberg, en $1822^{8}$. En 1835, fundó la prestigiosa revista Archiv der Politischen Ökonomie und Polizeiwissenchaft, fusionada en 1852 con el actual Zeitschift für die gesamte Staatswissenschaft (Journal of Institutional and Theoretical Economics). Más que como economista original, sin embargo, Rau es mencionado en la literatura económica como el erudito Profesor de Economía Política de la Universidad de Heidelberg, autor de la famosa obra Lebrbuch der politischen Ökonomie ${ }^{9}$. Publicada en 1826, la obra de Rau alcanzó gran popularidad, comparable en nuestros días, dicen Recktenwald y Streissler, con el actual Curso de Economía Moderna de Samuelson ${ }^{10}$, siendo durante muchos años el libro de texto utilizado en las universidades germanas y por los candidatos a la administración pública ${ }^{11}$. Traducida a varios idiomas europeos (francés,

${ }^{8}$ Sobre Rau y su pensamiento político-económico, véase Sinewe (1965), Tribe (1988, pp. 183-201) y Bowler (1996). Véase también Dickinson (1958, pp. 577-593), Beckerath (1964, pp. 683-684), Homberg (1971, pp. 93-107), Streissler (1990, pp. 154-157) y Theocharis (1993, pp. 148-164).

9 Véase, por ejemplo, Ingram (1899, p. 264), Pribram (1934, p. 122) y Ratti (1935, p. 864).

${ }^{10}$ Recktenwald (1987, p. 96) y Streissler (1990, p. 156).

${ }^{11}$ Una extensa y favorable reseña de esta obra puede verse en Legoyt (1854, pp. 376-392 y 344-356). En España, Manuel Colmeiro (1845, especialmente pp. 8, 15, 59 y 88), Catedrático de la Universidad de Santiago de Compostela, también menciona a Rau extensa y favorablemente. Excepciones notables fueron Cossa y, más recientemente, Schumpeter y Volker Hentschel. Cossa (1884, pp. 219-220) reconoce el carácter enciclopédico de la obra de Rau, «rica en ilustraciones estadísticas y bibliográficas», pero cree que «mayor originalidad e ingenio más agudo tuvieron algunos autores contemporáneos de Rau». Schumpeter $(1971$, p. 564, n. 70 ) es mucho más critico cuando escribe: «Rau tenía sin duda un buen sentido común, erudición y mediocridad. Y si otras cualidades más son necesarias para producir libros de texto que tengan éxito, no hay duda de que las ha tenido. Las 
holandés, ruso, sueco, polaco, servio, italiano y rumano) ${ }^{12}$, la obra alcanzó la octava (y última) edición en $1868^{13}$. Después de la muerte de Rau, su obra fue reescrita y publicada con diferente título en 1876 por Adolph Wagner y Erwin Nasse, quienes suprimieron todos los desarrollos matemáticos y gráficos ${ }^{14}$.

Si como pensador original Rau no ocupa un lugar destacado en la historia del pensamiento económico, hay que reconocerle, en cambio, el mérito de haberse anticipado a su tiempo en la defensa del uso de fórmulas matemáticas en el estudio de la economía. En efecto, frente a la entonces dominante escuela histórica alemana y a la oposición de destacados economistas de la época, para quienes la aplicación de las matemáticas al estudio de una ciencia esencialmente moral como la economía constituía incluso un falso, despiadado, inquietante y peligroso atentado contra el alma y la libertad humana ${ }^{15}$, Rau reconoció, ya en 1820 , las ventajas del

muchas ediciones de su Lebrbuch..., aun siendo indicativas, expresan el avasallador éxito del libro menos profundamente que el hecho de que Adolph Wagner considerara mejor retocar el texto que sustituirlo por otro nuevo. Rau ocupa un destacado lugar de maestro de la historia de la economía, aunque en favor de su texto no se pueda aducir gran cosa, salvo que comunicaba muy limpiamente una gran riqueza de datos factuales: eso era precisamente lo que el futuro abogado o funcionario público era capaz y estaba deseoso de asimilar». Y para Hentschel (citado por Bowler 1996, p. 13, n.), «Rau fue un simple cameralista y, como tal, un proponedor de concepciones científicas ilógicas».

${ }^{12}$ Según Popescu (1964, p. 453, n. 7), la obra de Rau fue traducida al castellano y publicada en Madrid, s/f., con el título Tratado de Economía Política. Lamentablemente, sin embargo, este autor no ha podido localizar dicha traducción.

${ }^{13}$ Rau conservó los mismos epígrafes en todas las ediciones, de modo que en las referencias a su obra se ha considerado conveniente citar las páginas y los epígrafes.

${ }^{14}$ Véase Rau (1876).

15 Uno de los genuinos representantes de esta corriente de pensamiento fue el profesor Wolowsky, destacado Miembro de la Academia francesa de ciencias morales y políticas. Según Wolowsky (1857, pp. LV-LVI, versalitas en el original), «las deducciones abstractas de la ciencia pura no nos dejan ciertamente sin inquietud, pues tratan al hombre como una fuerza material, mucho más que como una fuerza moral; en contacto con los procedimientos rigurosos de la especulación matemática, el hombre se convierte en una constante, para todos los tiempos y todos los países, cuando en realidad es una variable». Para el economista belga Émile de Laveleye (1883, pp. 102-103), «los hechos económicos emanan del libre albedrio humano y no de la concatenación necesaria de las leyes naturales», por lo que «la economía política reducida a las fórmulas abstractas de las leyes naturales es una escolástica más huera que la de la Edad Media». Y para Liesse (1888, p. 306), los economistas matemáticos eran «quirúrgicos con un escalpelo excelente y un bisturí mellado, que operaban maravillosamente a los muertos y martirizaban a los vivos». En fin, Karl Knies (1853, pp. 28, 353), destacado miembro de la vieja escuela histórica alemana exclamaba que, si se prescinde de la moral y del método histórico, la economía política carecía de entrañas. Mucho más decidido en la repulsa del método matemático fue el gran von Mises (1960, pp. 538, 542) cuando años más tarde escribió: «El método matemático ha de ser 
lenguaje matemático. En su traducción al alemán de la obra del economista ruso Storch, Rau sostiene que la oposición de este autor al uso del formulismo matemático es injustificada y se basa en la creencia errónea de su finalidad. Es cierto, escribe Rau, que «uno se equivoca si piensa que las expresiones algebraicas permiten calcular con exactitud los efectos producidos por múltiples concausas», pero añade, citando a Buquoy, «si se consideran tales las expresiones como meros signos conceptuales, como un lenguaje que supera ampliamente en brevedad y comodidad a nuestro lenguaje de palabras, entonces puede uno servirse de ellas con provecho para exponer más claramente enunciados concretos, sin perder de vista dónde las relaciones dejan de ser puramente matemáticas» ${ }^{16}$. En los apéndices que escribió como complemento a su traducción de la obra de Storch, Rau hizo amplio uso de fórmulas algebraicas para precisar las ideas de este autor e ilustrar su argumentación ${ }^{17}$. En su obra, Rau volvió sobre el tema y, tras reconocer que la economía constaba de dos partes claramente diferenciadas, una teórica y otra aplicada, escribió:

Cuando se examina la naturaleza de los Teoremas de la economía nacional nos encontramos con que se componen de: 1) Leyes simples, que expresan únicamente que una cierta causa debe producir, o tiende a producir, un determinado efecto. Todo hecho económico se funda a decír verdad en tales leyes, pero raramente sucede que un efecto dado sea neta y claramente el resultado de una sola causa; pues en general son diversas las causas que intervienen en la producción del mismo efecto, bien complementándose o combatiéndose entre sí, de forma tal que, o la más débil es anulada por la más fuerte, de tal manera que aquélla se reduce a un conato inútil, o resulta un efecto de índole mixta, en el que se reconoce la acción limitada de varias fuerzas. Estas leyes simples pueden ser expresadas como las de la física por medio de una fórmula matemática ${ }^{18}$.

recusado no sólo por su esterilidad. Se trata de un vicioso sistema que parte de falsos supuestos y conduce a erróneas conclusiones. Sus silogismos no sólo son vanos; desvian, además, la atención de los verdaderos problemas, deformando la concatenación existente entre los diversos fenómenos económicos [...] No existe la economía cuantitativa. Todas las magnitudes económicas que conocemos son datos de historia económica». «Los economistas matemáticos», añade Mises, «sírvense de símbolos algebraicos [...] creyendo que así sus razonamientos resultan más científicos. Fuertemente impresionan a las gentes cándidas e imperitas, cuando en realidad no hacen más que confundir y embrollar asuntos que quedan perfectamente aclarados en los libros de texto de contabilidad y aritmética mercantil». Y concluye: «Las ecuaciones formuladas por la economía matemática no pasan de ser inútil gimnasia mental».

${ }^{16}$ Storch $(1820, \$ 8$, p. 236).

${ }^{17}$ Véase, por ejemplo, Storch $(1820, \$ 17,19,55,67,105,120,131)$.

${ }^{18}$ Rau $(1841 \mathrm{~b}, \$ 10$, pp. 6-7). 
Y en una nota a pie de página, Rau describe las ventajas del uso de las matemáticas en el estudio de la economía en términos similares a los utilizados por Marshall años más tarde ${ }^{19}$ :

No pocos teoremas referentes a cantidades numéricas se pueden expresar de forma más clara y concisa por medio de fórmulas simples que mediante el lenguaje ordinario, mientras que fórmulas demasiado complicadas son, por el contrario, menos útiles para tales propósitos, puesto que es difícil recordar de memoria el significado de todos los símbolos. Por otra parte, muchas cuestiones de la economía política han dado también ocasión a investigaciones matemáticas, que no se pueden expresar bien si no es por medio de signos aritméticos.

Es importante destacar que, como ejemplo de esta última afirmación, Rau citó explícitamente las Recherches de Cournot. No está claro, sin embargo, cómo ni cuándo descubrió la obra, y aunque es probable que ya la conociese en 1841, cuando le envió su segundo trabajo a su amigo Quételet, y que la frase inicial acerca de las ventajas que ofrece el análisis geométrico frente a las fórmulas algebraicas utilizadas por algunos economistas en la determinación del precio de equilibrio se refiriese a Cournot, Rau no citó las Recherches en la edición revisada de la obra de ese mismo año, como erróneamente creen Schneider y Hennings ${ }^{20}$, sino en la quinta (y sucesivas), publicada en $1847^{21}$.

\section{III}

Si bien el interés de Rau por la aplicación de las fórmulas matemáticas al estudio de la economía se remonta, como hemos visto, al año 1820, su principal contribución al análisis gráfico data de 1841. En efecto, entre la numerosa correspondencia del famoso astrónomo, matemático y estadístico belga Adolphe Quételet (1796-1874) ${ }^{22}$ se encuentra una carta de

19 Véase, por ejemplo, Marshall (1885, p. 255; 1898, p. 39, y 1961, pp. X, 84, 781). En contra de quienes consideran a Marshall como el genuino representante de los economistas matemáticos, habría que señalar, sin embargo, que su actitud hacia la matematización de la economía fue cuando menos ambigua y poco transparente. Véase, por ejemplo, Vázquez (1995).

${ }^{20}$ Schneider (1960, p. 382) y Hennings (1979, pp. 6 y 10 , n. 19).

${ }^{21} \operatorname{Rau}(1847, \$ 10$, p. $10 ; \$ 45$, p. 56$)$.

22 La correspondencia de Quételet, depositada actualmente en los Archives de l'Académie royale de Belgique (Palais des Académies), ha sido inventariada por Wellens-De Don$\operatorname{der}(1966)$. 
Rau, de marzo de 1841 , en la que le comunica el resultado que acababa de obtener al aplicar las funciones cónicas al estudio de un problema de localización de mercados, resultado, dice, que aunque no tenga ningún interés práctico, le ha proporcionado, en cambio, un gran placer personal ${ }^{23}$. Sin duda, la respuesta de su amigo Quételet debió de ser alentadora, pues pocos meses después, el 19 de septiembre de ese mismo año, Rau le envió nuevamente unas hojas manuscritas, reproducidas en el Apéndice 1, como «otro ejemplo de matemáticas aplicadas a la economía política» ${ }^{24}$. Quételet publicó íntegramente este trabajo de Rau (con ligeras correcciones gramaticales del propio Quételet), junto con un extracto de su carta anterior, en el Bulletin de l'Académie royale des Sciences et Belles-Lettres de Bruxelles ${ }^{25}$. Como Secretario perpetuo de la Academia, Quételet defendió en una de las sesiones la publicación de estos trabajos de Rau, arguyendo que «aun cuando la aplicación de las teorías matemáticas a la solución de algunos problemas de economía política, no sea de utilidad práctica, no significa, sin embargo, que carezcan de interés» ${ }^{26}$. Claramente, como se comprueba en la versión castellana que se ofrece a continuación, el trabajo de Rau no sólo no carece de interés, como reconoció Quételet, sino que le acredita merecidamente como precursor del diagrama marshalliano de la oferta y la demanda:

La manera en que la concurrencia regula el precio de las mercancías ha sido expresada por varios economistas mediante fórmulas algebraicas, pero se llega quizá a explicaciones más claras haciendo uso de construcciones geométricas. Si la oferta de una mercancía es igual a 20 , y la demanda es igual a 24 , es claro que la sexta parte de los compradores no puede ser satisfecha. Tan pronto como esta relación sea conocida, los vendedores elevarán el precio, es decir, declararán su preferencia en favor de aquellos que superen a los demás en el pago. Se produce entonces una disminución

${ }^{23}$ Carta de Rau a Quételet, de 24 de marzo de 1841, Archives de l'Académie royale de Belgique (Palais des Académies), carpeta núm. 2089.

24 Archives de l'Académie royale de Belgique, carpeta núm. 2089.

${ }^{25}$ Véase Rau (1841a, pp. 148-152). Es inexplicable que Baumol y Goldfeld (1968, pp. 181-183), que publicaron un resumen en inglés del primer trabajo de Rau, y resaltaron la originalidad del mismo, hayan pasado por alto la importancia del segundo, limitándose a señalar «que describe la geometría elemental de las curvas de oferta-demanda». Lo mismo cabe decir de Theocharis (1983, pp. 89-90, n. 103, 116 y 119, n. 55), que cita la cuarta edición (1841) de la obra de Rau, sin referencia a su análisis gráfico, lo que sí hizo, en cambio, Homberg (1971, pp. 98 y ss.), siguiendo a Schneider (1960). Sin embargo, Hennings (1979) parece haber sido el primero que destacó merecidamente la importancia de las cartas de Rau a Quételet en la determinación gráfica del equilibrio competitivo de la of sta y la demanda.

${ }^{26}$ Rau (1841a, p. 148). 
de la demanda, ya que una parte de las personas dispuestas a comprar abandonan el mercado cada vez que aumenta el precio de demanda, puesto que encuentran menos ventajas en la compra; esto depende de la evaluación de la utilidad de la mercancía, de la urgencia de su necesidad, y de los recursos del comprador. Si los vendedores conociesen perfectamente las tendencias de los compradores, elevarían el precio demandado hasta aquel punto exactamente en el que todavía quedase el suficiente número de compradores dispuesto a pagar ese precio. Si se equivocan en sus previsiones, o bien reciben menos de lo que piden, o parte de la mercancía quedará sin vender, puesto que el número de compradores es demasiado reducido en comparación con la cantidad ofrecida. Sin embargo, podemos suponer que la demanda reducida y la oferta son iguales.

Sea $a b$ (fig. 1) la cantidad de mercancía ofrecida, cuando el precio, por ejemplo, de 100 kilos había sido de 25 francos, y sea ac la cantidad demandada. La línea $c d$ indicará la disminución de la demanda para precios más elevados; de modo que al precio de 37,50, la línea $c d$ de la demanda y la be de la oferta se cortan. El precio se fija, pues, en 37,50. Cuanto más útil y deseada sea una cosa, tanto menor será el decrecimiento de la demanda, de modo que podría suceder que las líneas, sean rectas o curvas, se dirijan de forma diversa hacia el eje o escala $A B$. Si la línea de demanda corta $A B$, entonces cesa la concurrencia de los compradores, y no queda más que uno solo que no puede en modo alguno ser superado en el precio.

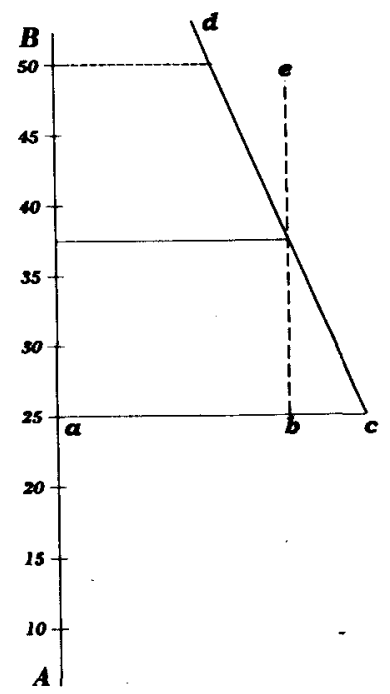

Fig. 1 
Sean ahora $a b$ y $c d$ (fig. 2) las curvas de demanda de dos mercancías. Para la misma oferta ef, se ve que el precio de una de las mercancías puede llegar a $\alpha$, mientras que el de la otra no puede aumentar más que hasta $\varepsilon$. Pero el supuesto de que la oferta permanece la misma es normalmente inexacto. Cada mercancía posee una forma particular, según la cual la cantidad ofrecida disminuye o aumenta según el precio del momento. Hay cosas cuya producción puede ser aumentada muy fácilmente en poco tiempo.

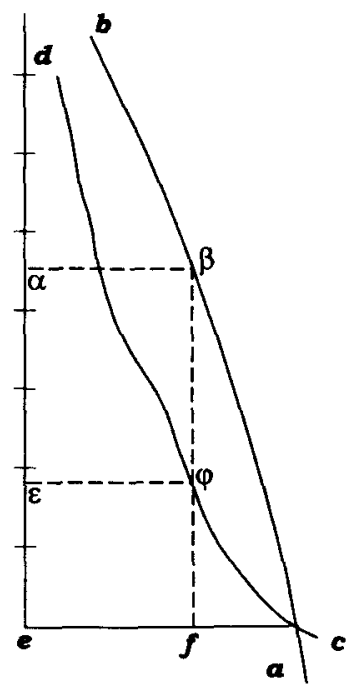

Fig. 2

En cuanto el precio aumenta, la oferta aumenta, según la curva $m n$, por ejemplo (fig. 3). Si $e c$ es la demanda actual, y $c d$ la curva de su disminución, el precio aumentará desde $e$ hasta $f$; para otra mercancía cuya demanda sea igualmente $e c$ y la línea de su decrecimiento $c g$, el precio aumentará hasta $b$. No será necesario desarrollar el caso opuesto, en el que la demanda es mucho menor que la oferta, puesto que entonces se opera la misma cosa en sentido inverso, por debajo del eje ec. Si se conociese la cantidad vendida de una cosa en diferentes épocas, por ejemplo, de una a otra semana, al mismo tiempo que los precios correspondientes, podríamos encontrar la curva de demanda por construcción, pero sólo en el caso de que ninguna otra de las causas influyentes viniese a perturbar el curso ordinario de las $\operatorname{cosas}^{27}$.

${ }^{27}$ Rau (1841, pp. 149-152). 


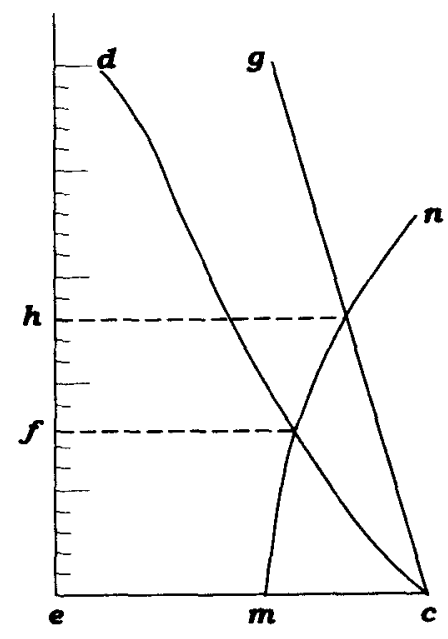

Fig. 3

La publicación por parte de Quételet de este trabajo de Rau probablemente indujo a su autor a incluir una versión más elaborada del mismo, con las tres figuras condensadas en una sola, en un nuevo apéndice $(\$ 154)$ en la cuarta edición revisada de su obra, publicada ese mismo año, «como otra exposición geométrica de la forma en que actúa la concurrencia» ${ }^{28}$. El contenido de este apéndice permaneció sin grandes cambios sustanciales en las sucesivas ediciones. En el Apéndice 2 se ofrece la versión castellana de la octava y última edición de la obra.

\section{IV}

Es indudable que Rau tenía una idea precisa de los conceptos de oferta y demanda y de la determinación del equilibrio competitivo a corto y largo plazo. En efecto, para Rau, las tres causas principales que regulan la formación del precio son: «el valor de los bienes que se intercambian, los

${ }^{28} \mathrm{Rau}(1841 \mathrm{~b}$, anexo $\$ 154$, pp. 525-527). Incidentalmente, el apéndice IV de Hennings (1979, pp. 21-23) no corresponde a la cuarta edición de la obra de Rau, como dice, sino a la sexta. 
costes de producción y la concurrencia de los oferentes y demandantes». $Y$ tras afirmar que «el valor que posee un objeto para nosotros representa el sacrificio que estamos dispuestos a hacer para obtener su posesión», Rau enuncia «como primera regla que el precio de un objeto no sobrepasa el valor que posee para el comprador ${ }^{29}$. Si la curva de demanda, dice Rau, que representa el precio máximo que los compradores están dispuestos a pagar por las distintas cantidades de la mercancía, es menor que la curva de oferta, que expresa el precio mínimo que los oferentes están dispuestos a aceptar, una parte de los vendedores es expulsada del mercado y el precio disminuye hasta que se restablezca la igualdad anterior. Lo contrario sucede, añade Rau, cuando la demanda excede a la oferta ${ }^{30}$. Y lo que es más importante, Rau fue plenamente consciente de que el efecto de las variaciones de la oferta y de la demanda sobre el precio del mercado depende de la pendiente de las curvas de oferta y de demanda o, en la terminología actual, de sus respectivas elasticidades, si bien hay que puntualizar que el concepto de elasticidad puntual de la demanda se debe a Marshall. En efecto, partiendo del supuesto de que las expectativas de precios elevados inducen un incremento de la producción, lo que se traduce en un aumento en la oferta del producto a largo plazo, Rau muestra claramente cómo la disminución del precio de equilibrio es mayor cuanto más rígida (menos elástica) es la curva de demanda. Por el contrario, dice Rau, el aumento del precio ocasionado por un incremento en la demanda es tanto menor cuanto menos inclinada (más elástica) es la curva de oferta. Es importante señalar también que en la sexta edición de su obra Rau expresó la variación experimentada por el precio de equilibrio en rigurosos términos trigonométricos ${ }^{31}$.

Por otra parte, hay que señalar que aun cuando Rau conociese las Recherches de Cournot, existen diferencias notables entre ambos autores. En primer lugar, Rau advierte claramente que su análisis es válido solamente en condiciones caeteris paribus, es decir, en el supuesto de que sólo varíe el precio de la mercancía, permaneciendo constantes las demás variables de las que depende la demanda (necesidad de la mercancía y medios o renta del consumidor). Contrariamente a Cournot, cuya curva de demanda, si bien reconoce su contenido empírico, no se basa en la utilidad marginal, como creen algunos autores ${ }^{32}$, sino que es fenomenológica, es decir, sin

${ }^{29} \operatorname{Rau}(1841$ b, $\$ 146 a, \$ 147$, p. 153$)$.

30 Ibid., $\$ 155$, p. 173 .

3 Rau (1855, anexo $\$ 154$, p. 583).

${ }^{32}$ Un resumen de interpretaciones contradictorias puede verse en Fray and Ekelund (1971). 
ninguna justificación subyacente, Rau reconoce explícitamente que la demanda es empírica y depende de la utilidad de la mercancía. Es más, Rau no sólo fue consciente de que el decrecimiento de la curva de demanda depende del decrecimiento de la utilidad marginal o «evaluación de la utilidad de la mercancía», sino también de la correspondencia entre la forma cóncava o convexa hacia el origen de coordenadas de la curva de demanda y el decrecimiento más o menos que proporcional de la utilidad marginal de la mercancía. En palabras de Rau, «cuanto más útil y deseada es una mercancía tanto menor es el decrecimiento de su curva de demanda», de modo que «para cada mercancía la modificación de las líneas de demanda y de oferta sigue sus propias leyes, y puede representarse por líneas de formas diversas, cóncavas o convexas, o a veces con curvaturas cóncavas y convexas a la vez» ${ }^{33}$. Contrariamente, para Cournot, el principio del decrecimiento de la función de demanda «no es más que la consecuencia matemática de la continuidad de las funciones» ${ }^{34}$. En efecto, al comienzo de su obra, Cournot ya advierte que prescinde deliberadamente de las ideas de utilidad, rareza y satisfacción de necesidades humanas por ser «accesorias, variables e indeterminadas por naturaleza, sobre las cuales no se podría asentar una teoría científica» ${ }^{35}$. Y más adelante, en el capítulo sobre la ley de la demanda (o ley del gasto), si bien reconoce que ésta «depende, evidentemente, de la utilidad del bien, de la naturaleza de los servicios que puede proporcionar o de las satisfacciones que procura» insiste nuevamente en que, como las causas morales que influyen en la demanda no se pueden enumerar ni medir, «es claro que no se debe esperar que la ley pueda expresarse mediante una fórmula algebraica» ${ }^{36}$.

En cuanto a la formación del precio de equilibrio, Cournot, como es sabido, fue el primero que lo expuso rigurosamente en términos gráficos y analíticos. Sin embargo, Cournot no se interesó directamente ni por el diagrama de la oferta y la demanda, ni por la estabilidad del equilibrio, sino por el efecto sobre el precio de equilibrio de un impuesto fijo sobre la mercancía. En efecto, tras demostrar por primera vez que el coste marginal creciente de la empresa representa su curva de oferta, y, por tanto, que un aumento del coste se traduce geométricamente en un desplazamiento de la curva de oferta en el sentido positivo del eje de los precios (abscisas) en la misma cuantía que el impuesto, Cournot concluye que,

\footnotetext{
33 Rau (1841b, anexo $\$ 154$, pp. 526-527).

34 Cournot (1969, p. 74).

35 lbid., p. 25.

36 Ibid., p. 70 .
} 
excepto en el caso excepcional de una demanda vertical, en todos los demás casos «el alza del precio será menor que el crecimiento del coste», y menor, por tanto, que la cuantía del impuesto ${ }^{37}$. Por el contrario, Rau no estaba familiarizado con el concepto de coste marginal y, como ya se ha indicado anteriormente, basó su análisis en el supuesto de que las expectativas de precios elevados inducen un aumento en la oferta del producto a largo plazo. Por último, como ha puntualizado Hennings, no fue Marshall, sino Rau, quien cambió los ejes de coordenadas con respecto a Cournot ${ }^{38}$, y a quien hay que atribuir la práctica actual entre los economistas, contraria a la convención matemática, de representar el precio en el eje de ordenadas y la cantidad demandada en el de abscisas.

Siguiendo a Hennings, Streissler, Humphrey y Theocharis atribuyen a Rau el descubrimiento independiente del diagrama marshalliano de la oferta y la demanda, pues creen que no leyó a Cournot y que supo de él a través de Quételet o por otro procedimiento indirecto ${ }^{39}$. Estos autores aducen con fundamento que, además de sus diferencias metodológicas, si Rau hubiese conocido el análisis gráfico de Cournot, lo hubiese citado explícitamente, dada su escrupulosidad en las referencias bibliográficas. Ahora bien, un hecho que parece haber escapado a la atención de estos autores es la extensa y correcta cita literal que hizo Rau de las Recherches ${ }^{40}$, lo que induce a creer que sí leyó la obra. Hennings señala, además, que aun cuando Quételet conociese probablemente a Cournot, las Recherches no figuran en el inventario de sus libros realizado por Bluff en $1881^{4 !}$. Ciertamente, unas notas manuscritas que Quételet escribió en 1871, con motivo del fallecimiento de su amigo el astrónomo real John Herschel ${ }^{42}$, ponen de relieve que sí conoció a Cournot. $Y$ este conocimiento data, cuando menos, de 1846, fecha en la que Quételet dice haber descubierto

${ }^{37}$ Ibid., p. 132; cursivas en el original.

${ }^{38}$ Hennings $(1979$, p. 6). Hay que señalar, sin embargo, que en su formulación matemática del duopolio, Cournot $(1969$, p. 112) escribió el precio como función de la cantidad demandada, y reconoció explícitamente que «es más cómodo emplear aquí la notación inversa». Por otra parte, no es enteramente exacto afirmar, como hace Groenewegen (1995, p. 150), siguiendo a Rashid (1977, p. 388), que Graves, en un trabajo que le envió el polifacético William Whewell, en 1849 , también consideró el precio como la variable dependiente. Véase John Thomas Graves, «Desiderata of Political Economy: Law of Demand and Supply», Whewell's Correspondence, Trinity College Library, Cambridge, R.18.8 ${ }^{12}$.

${ }_{39}$ Hennings (1979, pp. 5-6), Streissler (1990, p. 156), Humphrey (1992, p. 5) y Theocharis (1993, p. 154).

4" Rau (1847, $\$ 63$, p. 84).

41 Hennings (1979, p. 10, n. 21).

${ }^{42}$ Archives de l'Académie royale de Belgique, carpeta núm. 2273. 
la célebre obra de Cournot Exposition sur la théorie des chances et des probabilités ${ }^{43}$. En esta obra, que figura en los archivos de Rau ${ }^{44}$, el propio Cournot cita sus Recherches ${ }^{45}$. Más relevante es sin duda el hecho señalado también por Hennings de que las Recherches no figuren en la biblioteca de Rau, depositada actualmente en la Universidad de Michigan, ni en la de la Universidad de Heidelberg. Lamentablemente, sin embargo, la forma deficiente en que se llevó a cabo el inventario y catalogación de su voluminosa biblioteca (cuatro mil volúmenes y dos mil panfletos, aproximadamente) no permite obtener conclusiones definitivas ${ }^{46}$. Por otra parte, la correspondencia de Rau, que podía haber arrojado alguna luz sobre el tema, parece haberse perdido en su mayor parte, pues fue excluida del fondo de adquisición de la Universidad de Michigan, y quedó en poder de sus herederos, junto a algunas de sus obras. Por último, es asimismo probable que Rau descubriese a Cournot por mediación de su compatriota y colega Karl Heinrich Hagen (1785-1856). Profesor de Economía y Ciencia Política en la Universidad de Königsberg, Hagen publicó en 1844 un pequeño ensayo matemático sobre el comercio internacional, que reconoce haber sido motivado por las Recherches del importante matemático Cournot ${ }^{47}$. Sea como fuere, de lo que no cabe duda es de que Rau leyó las Recherches de Cournot ${ }^{48}$, si bien es probable que llegase independientemente a la determinación gráfica del equilibrio competitivo en 1841, antes de conocer

${ }^{43}$ Quételet (1846, pp. 387-388). Rau conoció la obra de Quételet, que le envió él mismo, y que citó en la quinta edición de su obra (Rau, 1847, $\$ 25$, p. 24).

44 En los archivos de Rau figura asimismo la obra de Cournot Principes de la théorie de richesses, que, como el propio autor reconoce, es esencialmente una versión no matemática de las Recherches.

${ }^{45}$ Cournot (1843, p. 223). Esta obra fue editada en alemán en 1849 por el Dr. C. H. Schnuse, con el título Die Grundlagen der Wabrscheinlichkeitsrechnung, leichtfasslich dargestellt für Philosopben, Staatsmänner, Juristen, Kameralisten und Gebildete überhaupt, Braunschweig, Leibroch. Hay que advertir, sin embargo, que, como indica el título, no se trata de una versión completa, sino «aligerada» de la obra original. Entre las numerosas notas a pie de página de las que se ha prescindido figura la relativa a las Recherches.

to Véase Dickinson (1958, esp. pp. 580-583). En contra de lo que cree Dickinson (ibid., p. 591), Rau no pasó por alto el pionero y contemporáneo trabajo de economía matemática abstracta de Cournot, pues lo cita, como hemos visto, en su obra.

${ }^{47}$ Hagen (1844, pp. 30-31). Según información de Kathryn L. Beam, Conservadora de la Biblioteca de la Universidad de Michigan, esta obra de Hagen no figura en los archivos de Rau. Cournot, por su parte, mencionó esta crítica favorable de Hagen. Véase Cournot (1863, p. 329 , n. 1 , y 1877 , p. 205 , n: 1$)$.

${ }_{48}$ Es significativo que, además de Hagen y Rau, otros dos economistas alemanes, Johann von Helferich (1852, p. 433) y Wilhelm Roscher (1854, p. 34), se hayan anticipado también a sus colegas europeos en el descubrimiento y valoración pública de la obra de Cournot. Es más, Cournot $(1877$, p. I) reseña este hecho y dice que frente al escaso interés que las Recherches han despertado «en Francia al menos, el libro ha sido traducido en Alemania, 
a Cournot, lo que explicaría que al citarlo por primera vez en la siguiente edición de su obra, aparecida en 1847 , lo hiciese en un contexto diferente. De ser cierta esta conjetura, se disiparían las dudas de los autores citados anteriormente acerca de la escrupulosidad y honestidad científica de Rau, cuyo conocimiento de la geometría de Cournot sigue siendo una cuestión abierta.

En cuanto a Marshall, no hay duda de que leyó a Cournot antes que a Rau. En una breve nota publicada en 1873, Marshall hizo una velada alusión a Cournot, cuando afirmó que el método de la oferta y la demanda era conocido desde hacía 35 años, es decir, desde 1838, fecha que coincide precisamente con la publicación de las Recherches de Cournot ${ }^{49}$. Sin embargo, la primera referencia escrita data de abril de 1876, cuando Marshall reconoció que hacía «algunos años, bajo la influencia del pensamiento de Cournot», dedicó mucho tiempo a estudiar la teoría del valor, citando explícitamente las Recherches en una nota a pie de página ${ }^{50}$. Que leyó a Cournot antes que a Rau, lo confirma también el hecho señalado por Whitaker de que en los primeros manuscritos sobre la oferta y la demanda Marshall dio por sentado, como Cournot, que la curva de demanda era decreciente, y sólo más tarde justificó su decrecimiento, como Rau, en el de la utilidad marginal de la mercancía. Asimismo, siguiendo a Cournot, y no a Rau, Marshall representó inicialmente el precio en el eje horizontal y la cantidad en el vertical ${ }^{51}$. Sin embargo, no está claro cómo Marshall descubrió a Cournot, si bien hay evidencia de que por entonces su obra era ya ampliamente conocida en los círculos científicos británicos, y este autor ha demostrado que William Whewell, polifacético Master del Trinity College (Cambridge), y Charles Babbage, célebre Profesor Lucasiano de matemáticas en Cambridge, adquirieron las Recherches de Cournot ${ }^{52}$.

donde en esa época se traducía todo». Sorprendentemente, sin embargo, no parece haber rastro alguno de dicha traducción.

49 Marshall (1873, p. 318).

so Marshall (1876, p. 600).

s1 Whitaker (1975, vol. 1, pp. 42, 45-46, y vol. 2, pp. 240-248).

52 Véase Vázquez (1997). Groenewegen (1990, p. 41 n. 4) cree que Marshall pudo haber descubierto a Cournot a través de Roscher, «quien se refirió al trabajo de Cournot como novedoso de forma insidiosa para atraer la atención de alguien como Marshall», pero Roscher (1854, p. 34, n. 4) cita a Cournot siguiendo claramente a Rau. 
En cuanto a Rau, Groenewegen ha comprobado que un ejemplar de la quinta edición de su obra, que Rau dedicó a Senior y a su amigo Quételet, se conserva actualmente en la Biblioteca de Marshall en Cambridge ${ }^{53}$. Marshall compró el libro de segunda mano en Alemania, y en su primera página figura el nombre del primer propietario, la fecha de 24 de diciembre de 1852 y la firma de Marshall. Como se indica más adelante, éste fue probablemente el ejemplar que Marshall le envió a Keynes en diciembre de 1910. Asimismo, hay evidencia de que Marshall adquirió la octava edición de la obra de Rau, pues figura, junto con la quinta edición, en el catálogo de la Biblioteca de Marshall ${ }^{54}$. Éste fue, a su vez, el ejemplar que Marshall le prestó a William Stanley Jevons, quien, con fecha del 12 de mayo de 1879, le escribe diciéndole que le devuelve el libro de Rau «que amablemente le envió hacía algunos años» 55 . En la segunda edición de su Theory of Political Economy, publicada ese mismo año, Jevons mencionó esta edición de la obra de Rau, y en el prólogo se refirió también a ella diciendo que su autor pertenece a aquella clase de «economistas que en modo alguno han empleado el tratamiento matemático de manera expresa o sistemática, sino que sólo incidentalmente han reconocido su utilidad introduciendo expresiones simbólicas o gráficas» ${ }^{56}$.

Es cierto que Marshall citó a Rau en las dos primeras ediciones de los Principios, pero lo hizo de forma incompleta y en relación con la distinción marginal que hace este autor entre el capital individual y el social ${ }^{57}$. Sorprendentemente, sin embargo, Marshall no mencionó la pionera des-

${ }^{53}$ Groenewegen (1995, p. 182, n. 66).

54 Ibid., p. 182, n. 67.

ss Whitaker (1996, vol. 1, pp. 107-108, carta núm. 59). No es, pues, correcta la afirmación de Groenewegen (1995, p. 154) de que Marshall le había prestado a Jevons el libro de Rau a comienzos de 1879 . Un año antes, Jevons (1878, pp. 473-474) ya había mencionado esta misma edición de Rau en su lista de obras de economía matemática. Con fecha 30 de junio de 1879, Marshall le contesta a Jevons diciéndole que ha recibido a salvo el libro de Rau. (Véase Whitaker 1996, vol. 1, p. 110, carta núm. 62, y Pigou 1966, p. 371).

${ }_{56}$ Jevons [(1957) 1965, pp. XXIV, 332]. La quinta edición de la obra de Jevons [(1957) 1965 , p. 325] incluye también otra referencia a Rau, tomada literalmente de la conocida bibliografía de economistas matemáticos de Irving Fisher (1898), con el comentario de este autor «muy ligeramente matemática». Incidentalmente, en Fisher y, por tanto, en Jevons, no figuran las ediciones quinta (1847) y sexta (1855) de la obra de Rau.

${ }_{77}$ En la primera edición de los Principios, Marshall cita parcialmente el título de la obra (Volkswirtschaftslehre) y dice que se debe a Rau «la sugestiva aunque no completamente satisfactoria distinción» entre el capital social y el individual; en la segunda edición sólo 
cripción gráfica de Rau del equilibrio competitivo de la oferta y la demanda, aun cuando el mismo reconoce en varias ocasiones estar familiarizado con las curvas de Rau. En efecto, en uno de sus artículos sobre la incidencia de los impuestos, Seligman afirma que Marshall había adoptado y extendido la idea del diagrama de la oferta y la demanda de Jenkin ${ }^{58}$. Con fecha 6 de abril de 1894, Marshall le escribe precisándole que acaba de leer su artículo, y que un año o dos antes de que Jenkin hubiese leído su trabajo en Edimburgo él ya había expuesto lo esencial de sus curvas sobre el monopolio en Cambridge, y publicado después una breve nota con motivo de la presentación de su alumno Cunynghame de una máquina para dibujar hipérbolas equiláteras. «Mis obligaciones son únicamente con Cournot, no con Fleeming Jenkin, ni con Dupuit», afirma categóricamente Marshall. Y, olvidando inexplicablemente que Rau incluyó su análisis gráfico de las curvas de oferta y demanda en la cuarta y sucesivas ediciones de su obra, añade: «La forma de las curvas usadas por él [Jenkin] es similar a la de las curvas usadas en las primeras ediciones de los Volkswirtschaftslebre de Rau. Las vi en la segunda edición de ese libro, creo. Pero no están en la única edición que tengo, la octava» ${ }^{59}$.

Dieciséis años más tarde, en diciembre de 1910, Marshall volvió sobre el tema, y en una carta a Keynes, le dice:

He encontrado las curvas de Rau al final de la que según veo es la quinta edición, que le adjunto. Si el Profesor Liefmann aún está con usted, puede estar interesado en ellas. Encuentro su conversación muy instructiva. Usted puede estar interesado en estas charlas. He visto por supuesto el primer trabajo de Fleeming Jenkin en Recess Studies 1870, pero no guarda relación con la breve disertación que di en la Sociedad Filosófica de Cambridge (véase los Proceedings de octubre 1873) para explicar los usos de la célebre máquina de H.H. Cunynghame para dibujar hipérbolas equiláteras en relación con los valores del monopolio. En ese trabajo, sin embargo, expliqué el excedente de los consumidores (entonces le llamé «Renta»), que creí era de mi propia cosecha, pues no sabía nada de Dupuit. Por supuesto, lo necesitaba para la curva que en lo sucesivo llamé «Curva de compromiso de beneficio». Maxwell se levantó y dijo que parte del trabajo le recordaba al de Fleeming Jenkin, refiriéndose por supuesto al artículo en los RSE proceedings del 71-2: y eso me inquietó, pues no había visto el trabajo. Cuando finalmente se publicaron mis Principios, Jenkin me escribió una

menciona el nombre de Rau, y prescinde de ambas referencias en las sucesivas ediciones de la obra. Marshall (1961, vol. II, p. 782).

${ }^{58}$ Véase Seligman (1892, pp. 155-156, n. 1).

59 Whitaker (1996, vol. 2, p. 106, carta núm. 443). 
atenta carta ${ }^{60}$, semejante a la que Walras me había escrito sobre la múltiple intersección de puntos, estableciendo la prioridad de su publicación, y me di cuenta entonces de que Jenkin había ido mucho más lejos de lo que yo había inferido de Recess Studies. Debí haberlo dicho así ayer.

Y en una postdata, Marshall le dice: «No hay prisa en la devolución de Rau» ${ }^{61}$.

En relación con la alusión que hace Marshall a James Clerk Maxwell (1831-1879), célebre profesor de Física en Cambridge, Groenewegen sospecha acertadamente que, como él y Marshall eran miembros y se conocían de la Sociedad Eranus, y Maxwell era además amigo y corresponsal de Jenkin, pudo muy bien haberle alertado acerca de la interesante contribución de Jenkin, la cual, añade, no sólo había aparecido en una publicación que no era difícil de obtener, sino particularmente por cuanto versaba sobre un tema en el que Marshall estaba entonces ocupado ${ }^{62}$. Ciertamente, el propio Marshall confirmó las sospechas de Groenewegen en una carta que le escribió a Keynes ocho días después de la intervención de Maxwell, en la que «incidentalmente» reconoce que su breve disertación en la Sociedad Filosófica de Cambridge le «sugiere la curva del Excedente de los Consumidores, que hube de mostrar separadamente, y que motivó las observaciones de Clerk Maxwell. Habló mucho y fue muy interesante. Pero no puedo recordar lo que dijo» ${ }^{63}$. Pero Marshall olvidó no sólo su interesante conversación con Maxwell, sino también la opinión que años antes le habían merecido los trabajos de Jenkin y Rau. En efecto, en su crítica recensión de la Theory de Jevons, en abril de 1872, Marshall contrapuso la claridad y tersura de los «diagramas o representación gráfica, como le llama el Profesor Fleeming Jenkin», a la complejidad del lenguaje matemático ${ }^{64}$. $\mathrm{Y}$ en una nota a pie de página, en las primeras ediciones de los Principios, Marshall reconoció que el método gráfico seguido en el capitulo sobre las variaciones de la demanda y la oferta era similar al adoptado por Dupuit en 1844, e, independiente, por Fleeming Jenkin (Edinburgh

${ }^{60}$ Según Whitaker $(1996$, vol. 3, p. 275, n. 8) no hay rastro de esta carta.

${ }^{61}$ Carta de Marshall a Keynes, de 4 de diciembre de 1910, en Whitaker (1996, vol. 3, pp. 274-275, carta núm. 989), parcialmente reimpresa también en Groenewegen (1995, pp. 162-163).

${ }^{62}$ Groenewegen (1995, p. 163).

${ }^{63}$ Carta de Marshall a Keynes, de 12 de diciembre de 1910, en Whitaker (1996, vol. 3 , p. 276 , carta núm. 990$)$.

it Véase Pigou (1966, p. 99). 
Philosopbical Transactions) en $1871^{65}$. Y entre los papeles de Marshall, su sobrino Claude Guillebaud encontró una hoja manuscrita suya, arrancada de la tercera edición (1895) de los Principios, con el siguiente comentario añadido al final de dicha nota a pie de página:

Las curvas de Fleeming Jenkin tienen una forma peculiar, distinta de todas aquellas con las que estoy familiarizado, a excepción de las que Rau añadió como apéndice a las primeras ediciones de su Volkswirtfchaftslebre. Ni Rau ni Jenkin se refieren a ningún predecesor. Vi el trabajo de Rau antes de ver el artículo de Jenkin en Recess Studies publicado en 1870; pero incluso antes de eso lo había aprendido de Cournot y von Thünen. Lo esencial de las curvas de ese capitulo lo expuse en clases en 1870 o antes; las curvas referentes a los monopolios pertenecen a una etapa considerablemente posterior de mi trabajo, y fueron expuestas en la Sociedad Filosófica de Cambridge en $1873^{66}$.

Al margen de Ja errónea insistencia de Marshall en que Rau incluyó su análisis gráfico en las primeras ediciones de su obra, de ser cierto que lo descubrió antes que a Jenkin, y a éste lo mencionó en su reseña de la obra de Jevons, en 1872 , no hay duda de que antes de 1873 Marshall ya conocía las curvas de Rau. En su carta del 2 de julio de 1900 a su amigo John Bates Clark, Marshall le confiesa que leyó a Cournot en 1868, y que no pudo leer a von Thünen hasta 1869 o 1870 , por no saber entonces bastante alemán ${ }^{67}$. De acuerdo con Keynes ${ }^{68}$, Marshall se trasladó a Dresden en 1868 para aprender el idioma y poder leer a Kant en el original. Volvió a Alemania y vivió en Berlín durante el invierno de 1870-1871, donde entró en contacto con los trabajos de varios economistas alemanes, particularmente Roscher. Es, pues, muy probable que haya sido en esa fecha cuando Marshall descubrió a Rau, lo que viene a confirmar el hecho de que lo leyera antes que a Jenkin, a quien descubrió, si creemos a Foxwell ${ }^{69}$, en la primavera de 1870 .

${ }^{65}$ Marshall (1961, vol. 1, p. 476). Como ha puntualizado Rodríguez Braun (1995, p. 321), Marshall cita a Jenkin de forma doblemente incorrecta: en cuanto al vítulo de la revista y al año de publicación.

to Marshall (1961, vol. 2, p. 534).

67 Reimpresa en Whitaker (1996, vol. 2, pp. 282-283, carta núm. 617), y parcialmente en Pigou (1966, pp. 412-413).

${ }^{68}$ Ibid., pp. 10-11.

${ }^{69}$ Carta de H. S. Foxwell a John Maynard Keynes, de 24 de abril de 1925, en Whitaker (1975, vol. 2, p. 45 , n. 26). 


\section{VI}

En diversas ocasiones, Marshall ha reivindicado la originalidad de sus aportaciones científicas y ha hecho gala de su honestidad intelectual. En su conocida carta a John Bates Clark, de 24 de marzo de 1908, tras reconocer las dudas y angustia que le asaltaron en los primeros años acerca del reconocimiento que debía hacer a los demás, Marshall dice: «Mi norma ha sido citar en una nota a pie de página a cualesquiera de quien supiese que había dicho algo antes que yo lo hubiese publicado, aunque ya lo hubiese dicho yo en clase muchos años antes de saber que pudiera habérsele ocurrido a él» ${ }^{70}$. Y años antes, en julio de 1894, con motivo de una carta de Seligman, en la que éste parece haberse disculpado ante Marshall diciéndole que era natural suponer que había seguido a Jenkin en su análisis gráfico de la teoría de los impuestos, Marshall le responde un tanto molesto que siempre reconoció sus deudas y «que mencionó intencionadamente a Jenkin para dar a entender que no le debía nada». Y, a modo de justificación, afirma categóricamente: «He hecho una cuestión de honor reconocer mis obligaciones, siempre que las pueda rastrear y cuando no son obvias» ${ }^{71}$. Lamentablemente, sin embargo, no es ésta la conclusión que se deriva de este trabajo. Y, si bien es cierta la afirmación keynesiana de que la geometría de Marshall va mucho más allá que la de sus predecesores, Rau incluido, no es menos cierta también la conocida acusación schumpeteriana de la falta de generosidad de Marshall con todos aquellos cuyos trabajos están íntimamente relacionados con los suyos. Ciertamente, en el caso de Rau, la generosidad es una cualidad conspicuamente ausente en el comportamiento de Marshall.

En el mismo sentido, Groenewegen ha escrito más recientemente que, en cuestiones de prioridad, «Marshall oscureció deliberadamente sus deudas proclamando que él había obtenido independientemente esos resultados en clases, y haciendo oscuras referencias a la ayuda que le proporcionaron en esas materias Cournot y von Thünen» ${ }^{72}$. Claramente, esta certera frase de Groenewegen podía haber sido escrita a propósito de Rau. En efecto, en diversas ocasiones Marshall insistió en que su deuda era solamente con Cournot, o con él y von Thünen, pero no con Jenkin ni

${ }^{70}$ Carta de Marshall a Clark, 24 de marzo de 1908, reimpresa en Pigou (1966, p. 416), y en Whitaker (1996, vol. 3, pp. 182-184, carta núm. 899).

${ }^{71}$ Carta de Marshall a Edwin Robert Anderson Seligman, de 10 de julio de 1894, en Whitaker (1996, vol. 2, p. 117, carta núm. 452).

72 Groenewegen (1995, pp. 162, 777). 
Dupuit. Sin embargo, Marshall no mencionó ni a Cournot, cuya deuda es ciertamente indiscutible, ni a von Thünen, cuyo reconocimiento, en palabras de Groenewegen y Whitaker ${ }^{73}$, es difícil de aceptar y carece en general de fundamento. En cambio, en la segunda y sucesivas ediciones de los Principios, Marshall afirma que su análisis gráfico es en cierta medida similar al de Dupuit y Jenkin, pero se olvida de Rau, pese a reconocer en notas y correspondencia privadas que las curvas de Rau son semejantes a las de Jenkin y, además, que lo descubrió mucho antes que a éste. Es cierto que Marshall citó a Rau en las dos primeras ediciones de su obra, pero lo hizo de forma incompleta y marginal, y no donde debía hacerlo, o sea, en relación con su análisis gráfico, lo que no le impidió, sin embargo, recomendar años más tarde las curvas de Rau al Profesor Liefmann y, probablemente, a Jevons. Finalmente, sorprende la reiterada insistencia de Marshall en que el propósito de su breve disertación (dos páginas escasas) en la Sociedad Filosófica de Cambridge, en octubre de 1873, no fue otro que el de servir de introducción a la máquina inventada por su discípulo Cunynghame para trazar hipérbolas equiláteras ${ }^{74}$, pues, si bien hay evidencia de la temprana preocupación de Marshall por la geometría de la oferta y la demanda, es difícil de aceptar, en cambio, que la prioridad de sus diagramas se base en ese trabajo, que no contiene, además, ningún gráfico, y aún antes ya había leído a Cournot y a Rau. En resumen, no todo está en Marshall, como creía Lavington, sino en sus predecesores también, si uno se toma la molestia de hacerlo aflorar. Tampoco el conocido diagrama de la oferta y la demanda que lleva el nombre de Marshall apoya su pretendida modestia y generosidad con los demás; más bien ilustra la denominada ley epónima de Stigler, según la cual «las teorías científicas raramente llevan el nombre de su primer descubridor» ${ }^{75}$.

${ }^{73}$ Ibid., especialmente pp. 151, 162, 777, y Whitaker (1975, vol. 2, pp. 248-250).

${ }^{74}$ Véase, por ejemplo, Marshall (1961, vol. 2, pp. 7-8, 37-38, 534); Cartas de Marshall a Edgeworth, de 9 de marzo de 1881, y a Walras, de 1 de noviembre de 1883, en Whitaker (1996, vol. 1, p. 134, carta núm. 94, y pp. 169-170, carta núm. 133); carta de Marshall a Seligman, de 6 de abril de 1894, en Whitaker (1996, vol. 2, p. 106, carta núm. 443); cartas de Marshall a Keynes, de 4 y 12 de diciembre de 1910, en Whitaker (1996, vol. 3 , pp. 274-276, cartas núm. 989 y 990), y carta de Marshall a Cunynghame, de 7 de abril de 1904, en Pigou (1966, pp. 448-450), y en Whitaker (1996, vol. 3. pp. 79-80, carta núm. 793).

75 S. M. Stigler (1980, p. 147). Véase también G. Stigler (1992, p. 78 ). 


\section{APÉNDICE 1}

Facsímil del escrito de Rau a Quételet, de 19 de septiembre de 1841

$$
\begin{aligned}
& \text { filted at torion, lo } \\
& \text { 19. or. truा. }
\end{aligned}
$$

$$
\text { Ntemeriene!' }
$$

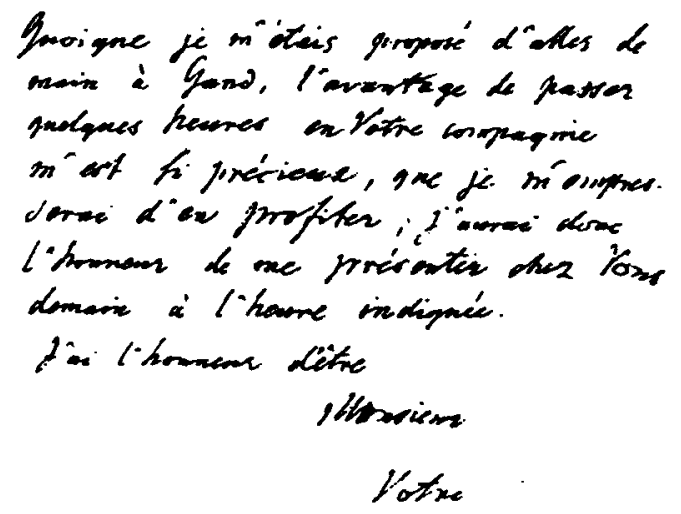

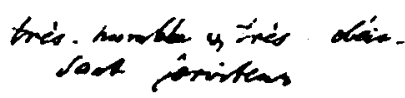
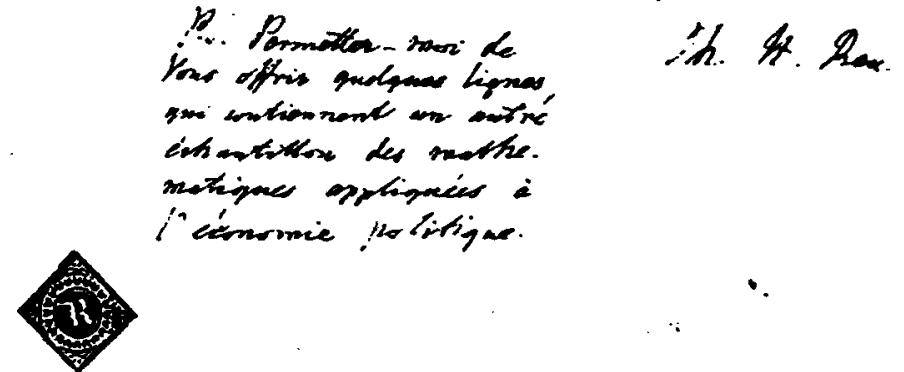


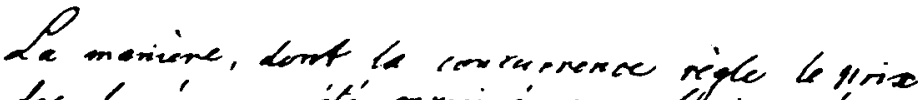

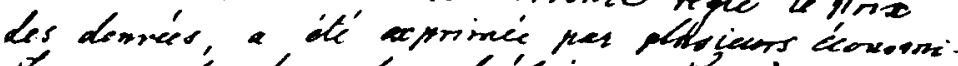

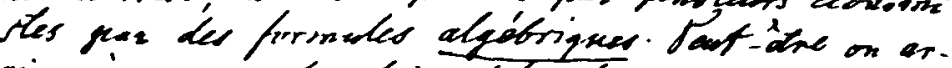
rive a we eophicatione folus clacie wopewn onf une construction fémetrizue, qui L "ailleurs perait almottre Les deudoppemens catínieurs.

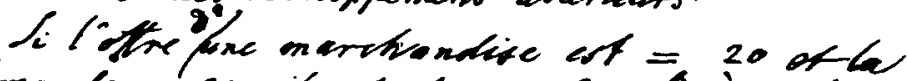
demente $=24$, it est dacie on in faidine les $x$ -

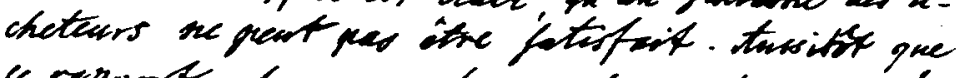

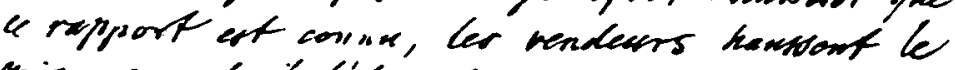

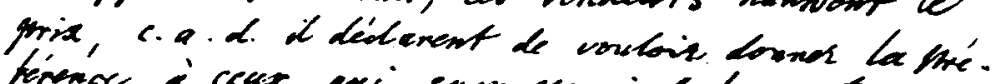

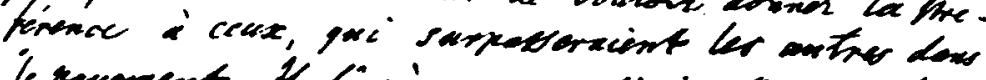

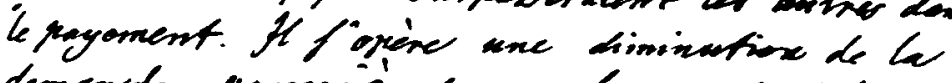

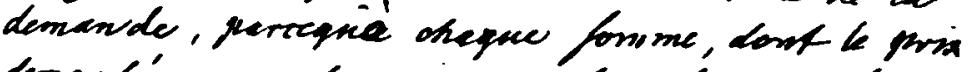

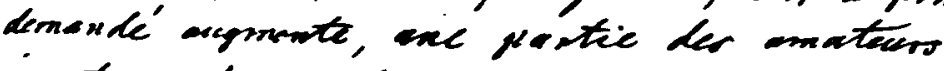

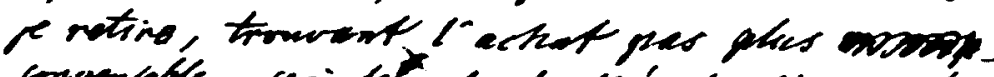

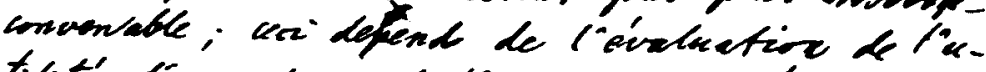

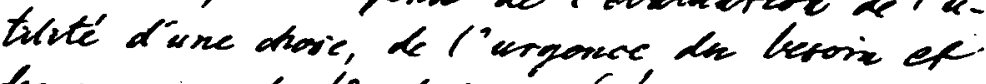

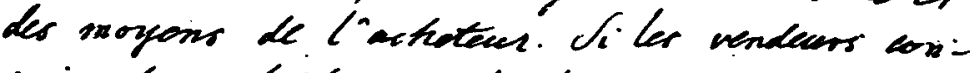

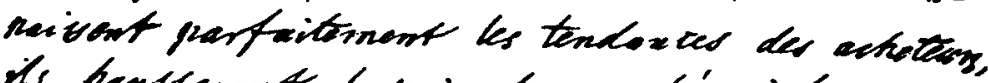

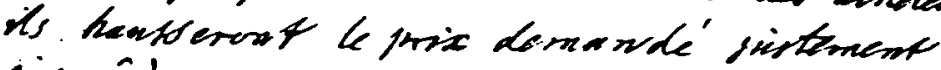

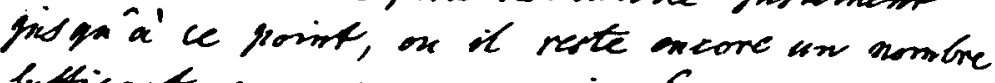
fuffisant, powe pages ceprix. $S_{\pi}$ as ga its te

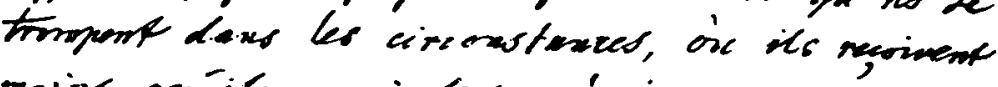

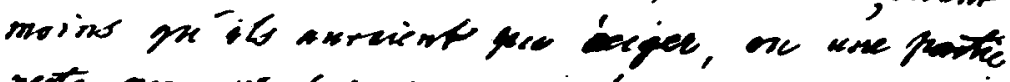
reste mow vendue, peroeque be mosobre des eckitare off troxe redarit an ropreort de la grastite

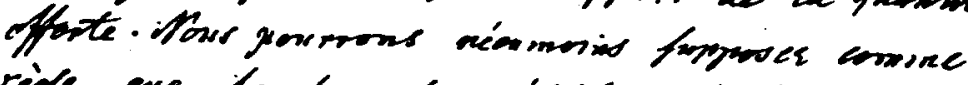

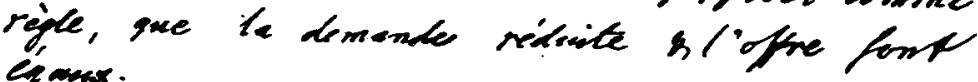
\&anas. 


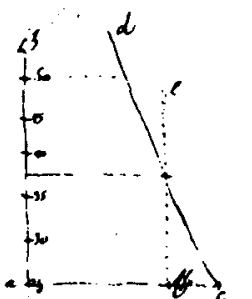

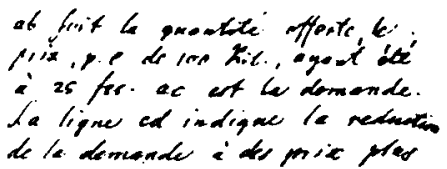

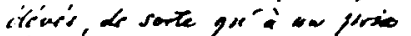

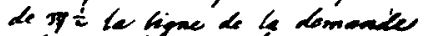
cot of arte \& lieftre be fo trenchirat. Le pric fe five

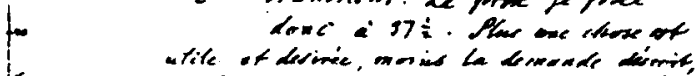

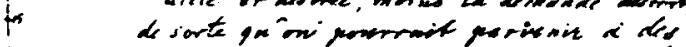

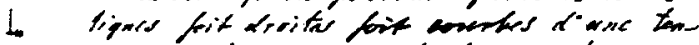

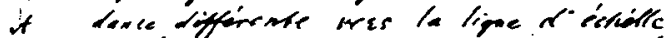

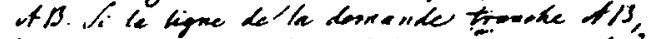

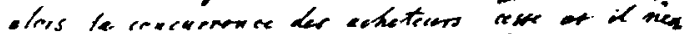

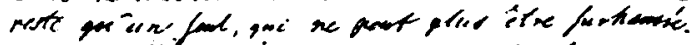

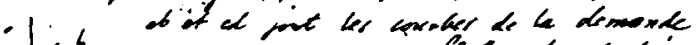

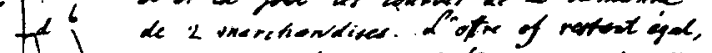

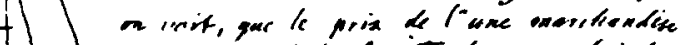

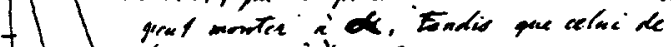

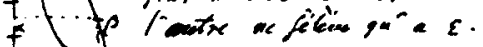

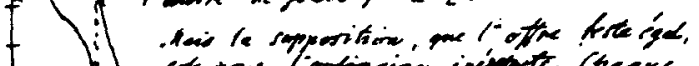

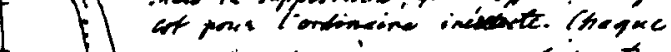

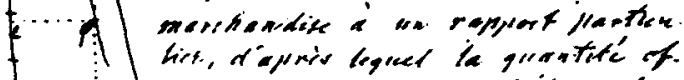

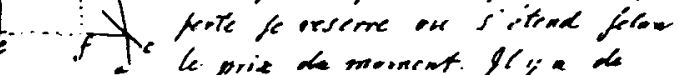

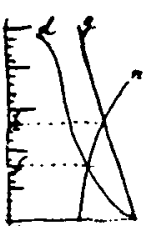
Le prit de mosurnt. lly a th cheass. lont le produrtion part itue tois fevilement angmentie en pres

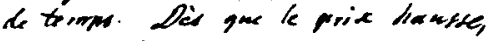
lofpe fitted, p.e. fow bente

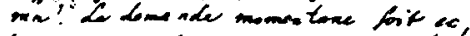

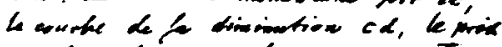

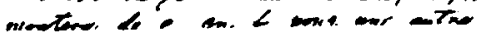

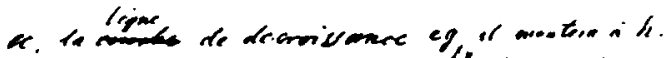

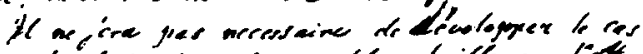

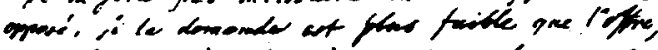

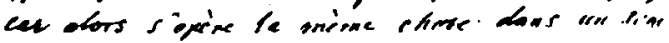
imerese, on distods.

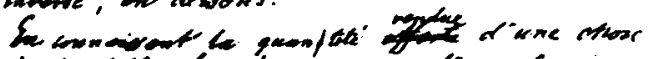

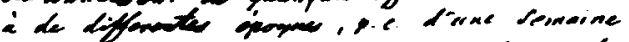

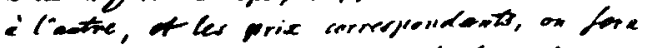

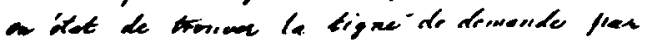

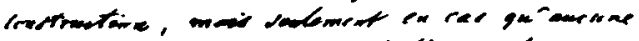

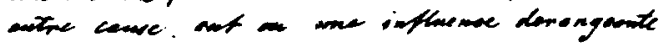




\section{APÉNDICE 2}

Anexo 154 de la octava edición de la obra de $\operatorname{Rau}(1868, \$ 154$, pp. 368-370)

La ley de la economía política según la cual el precio viene determinado por la competencia en el caso de que la demanda y la oferta no sean iguales se puede hacer fácilmente intuible por medio de la figura adjunta. En la línea $A B$ se consignan los diferentes precios en dinero de una mercancía, de 0 a 45 florines (o táleros, francos, etc.). En las líneas horizontales $A b$, los segmentos $a b, a^{\prime} l$, $a^{\prime \prime} o$, indican la magnitud de la demanda y de la oferta. La demanda decrece escalonadamente cuando resulta necesario pagar un precio mayor que hasta ahora. Suponiendo que el precio haya sido de 10 florines, la demanda a ese precio vendría expresada por $a b$, y la oferta por $A e=a c$. Los vendedores, comprensiblemente, exigen más de 10 florines, y una parte de los compradores se retrae. Ahora bien, si a 24 florines la demanda ha decrecido tanto que iguala la cantidad ofrecida, y consiguientemente ambas magnitudes coinciden en la longitud $a$ " $m$, entonces ése será el precio por el cual ambas partes pueden conseguir su propósito. La línea ecmd indica la oferta constante, mientras que la bbmg indica cómo disminuye paulatinamente la demanda al aumentar el precio exigido, y en $m$, donde ambas líneas se cortan, se conoce en la escala $A B$ el precio y cómo se va fijando. La línea que representa la demanda puede ser también curva, como la fbonpi, es decir, la demanda decrece más débilmente al principio y más fuerte después, y son incluso pensables curvas de otras formas: cóncava, convexa, ondulada y similares. Para

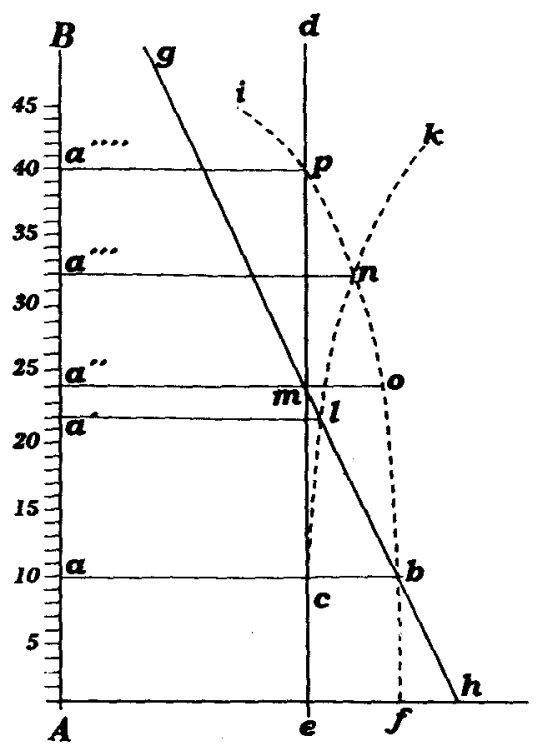


la misma oferta, la citada curva de demanda sólo llegaría a cortar la línea de oferta en $p$, y el precio ascendería a 40 florines. Los rectángulos a"me $A$ y a "' peA expresan el ingreso total, esto es, el producto del precio 24 o 40 por la cantidad de mercancía vendida, por ejemplo 80 quintales. Cuanto más fuertemente se acerque la línea de demanda a la escala $A B$ tanto más decrece la demanda y tanto menor será el aumento del precio. Esto quedará representado por el ángulo $b h A=m b a$. En mercancías de valor menor, este ángulo es más agudo, el encuentro de $b m g$ con ed se alcanza en un lugar más bajo, por ejemplo al precio de 15 florines. Para una línea de demanda recta, como la $b b g$, la magnitud del precio se mide por el valor del ángulo gba, puesto que $\mathrm{cm}=(a b-a c)$ tang.gba. A todo esto, no hay que olvidar que las unidades en la escala de precios $A B$ y los segmentos en $A b, a b, \ldots$ no guardan coherencia; $a c$, por ejemplo, podría representar un importe de 100 o 1.000 quintales, mientras Aa" de 24 monedas suizas o dólares. Es arbitrario qué importe se asignará a la línea vertical y a las horizontales, y sólo si esto ha sucedido de un modo determinado cabe aplicar para $\mathrm{cm}$ el anterior cálculo. Por ejemplo, si la longitud de 1 florín en $A B$ se tomase como equivalente a una magnitud de 20 quintales en $A b$, y si las demandas fuesen para 20 florines 1.000 quintales, para 25 florines 900 quintales, y si también la demanda decreciese siguiendo una línea recta, entonces sucedería que el ángulo $m b A=45 .^{\circ} ; \mathrm{cb}=\mathrm{cm}$, y la demanda a 30 florines serían 800 quintales, de modo que para una oferta equivalente el precio sería igual a esa cantidad ${ }^{76}$. A menudo crece la oferta cuando hay perspectivas de un precio más alto, tal como lo indica la curva clnk. Al precio de 22 florines, la coincidencia de la oferta y la demanda se produce en $a^{\prime} l$; a 32 florines, para la línea de demanda $f b o i$, se da en $n$. Prolongando $A B$ y bg hasta que se corten más arriba se obtendría el precio que pagaria el demandante deseoso de comprar la única pieza, un único quintal ofrecido, etc., como sucede en una subasta. El dibujo también es apto para el caso de una oferta que excede a la demanda, cuando, por ejemplo, $a b$ indica la oferta y ac la demanda, sólo que entonces las cifras de precios van disminuyendo hacia arriba $(10,8,6, \ldots)$ y también entonces la demanda crecería manifiestamente al descender el precio exigido.

\section{BIBLIOGRAFÍA}

Baumol, William J., y Goldfeld, Stephen M. (1968): Precursors in Mathematical Economics: An Anthology, London, London School of Economics and Political Science.

BECKERATH, Erwin von (1964): «Rau, Karl Heinrich», en Handwörterbuch der Sozialwissenschaften, vol. 8, Stuttgart, Gustav Fischer, pp. 683-684.

it Para estos datos, la demanda viene dada por la ecuación $p=70-1 / 20 q$, donde $p$ denota el precio y $q$ la cantidad de demanda. Obviamente, si se re-escala el eje de las cantidades, de modo que la nueva unidad de medida sea 20 veces menor que la anterior, la curva de demanda se transforma en una recta decreciente, con pendiente igual a $-45 .^{\circ}$, resultado que Rau pudo haber obtenido directamente sin más que ajustar convenientemente la cantidad demandada o el precio. 
Bowler, Richard Carl (1996): Bildung, Bureaucracy, and Political Economy: Karl Heinrich Rau and the Development of German Economics, University of California, Los Angeles: Inaugural-Dissertation.

Colmeiro, Manuel (1845): Tratado elemental de economia política ecléctica. I. Teoría económica, Madrid, Librería de los señores viuda e hijos de D. Antonio Calleja.

Cossa, Luigi (1884): Guia para el estudio de la Economía Politica, Valladolid, Imprenta y librería de la viuda de Cuesta e Hijos. Traducción castellana de Guida allo studio dell'economia politica, Milano, Ulrico Hoepli Editore, 1876.

Colnnot, Antoine A. (1863): Principes de la théorie des richesses, Paris, Hachette.

- (1877): Revue sommaire des doctrines économiques, Paris, Hachette.

- (1969): Investigaciones acerca de los principios matemáticos de la teoria de las riquezas, Madrid, Alianza Editorial. Versión castellana de Recherches sur les principes mathématiques de la théorie des richesses, Paris, Hachette, 1838.

- ([1843] 1984): Exposition de la Théorie des Chances et des Probabilités, Paris, Librairie ]. Vrin.

DiCKINSON, Z. Clark (1958): «The Library and Works of Karl Heinrich Rau», Zeitschrift für die gesamte Staatswissenschaft, vol. 114, núm. 4, pp. 577.593.

EDGEWORTH, Francis Y. (1894): «The Theory of International Values, III», Economic Journal, vol. IV, núm. 16, diciembre, pp. 606-638.

FISHER, Irving (1898): «Cournot and Mathematical Economics», Quarterly Journal of Economics, vol. 12, enero, pp. 119-138 y 238-244.

Fray, C. L., y Ekelund, Robert B. (1971): «Cournot's Demand Theory: A Reassessment», History of Political Economy, vol. 3, núm. 1, pp. 190-197.

Groenewegen, Peter (1990): «Neoclassical Value and Distribution Thieory: The English Speaking Pioneers», en Henning, K., y Samuels, W. (eds.): Neoclassical Economics Theory, 1870 to 1930, Boston, Kluwer Academic Publishers, pp. $13-51$.

- (1995): A Soaring Eagle: Alfred Marshall, 1842-1924, Aldershot, Edward Elgar.

HAGEN, Karl Heinrich (1844): Die Notwendigkeit der Handelsfreibeit für das Nationaleinkommen, matematisch nachgewiesen, Königsberg, Gräfe \& Unzer.

HelFERICH, Johann von (1852): «Johann Heinrich von Thünen und sein Gesetz über die Theilung des Produkts unter die Arbeiter und Kapitalisten», Zeitschrift für die gesamte Staatswissenschaft, vol. 8, núms. 2 y 3, pp. 393-433.

Hennings, Klaus H. (1979): «Karl Heinrich Rau and the Graphic Representation of Supply and Demand», Fachbereich Wirtschaftswissenschaften, Universität Hannover: Diskussionspapier, Serie C, Nr. 35.

- (1980): «The Transition from Classical to Neoclassical Economic Theory: Hans von Mangold», Kyklos, vol. 33, núm. 4, pp. 658-681.

HOMBERG, Gerhard (1971): Die Vertreter der mathematischen Nationalökonomie im deutschsprachigen Raum vor dem Erscheinen des Cournotschen Werkes (1838), Freiburg im Breisgau: Facultät der Albert-Ludwigs-Univertität, Inaugural-Dissertation.

Humphrey, Thomas M. (1992): «Marshallian Cross Diagrams and Their Uses before Alfred Marshall: The Origins of Supply and Demand Geometry», Federal Reserve Bank of Richmond Economic Review, vol. 78 (2), marzo y abril, pp. 3-23. INGRAM, John Kells (1899): «Rau, Karl Heinrich», en Inglis Palgrave, R. H. (ed.): Dictionary of Political Economy, vol. III, London, Macmillan and Co., p. 264. 
Jevons, William Stanley (1878): «Bibliographie des ouvrages relatives a l'application des mathématiques a l'économie politique», Journal des Économistes, vol. 4, núm. 12, diciembre, pp. 470-477 (introducción de Léon Walras).

- ([1957] 1965): The Theory of Political Economy, New York, Augustus M. Kelly.

Keynes, John Maynard ([1925] 1966): «Alfred Marshall, 1842-1924», en PIgou, A. C. (ed.), pp. 1-80.

KNIEs, Karl Gustave Adolph (1853): Die Politische Ökonomie vom Standpunkte der geschichtlichen Methode, Braunschweig, C.A. Schwetschke und Sohn.

LAVELEYE, Émile de (1883): «Les lois naturelle et l'object de l'économie politique», Joumal des Économistes, vol. 22, núm. 4, abril, pp. 92-104.

LegorT, Alfred (1854): «Fondements de L'Économie Politique Pure et Appliquée, par M. Rau», Journal des Économistes, vol. 2, núm. 6, junio, pp. 376-392, y vol. 3, núm. 9, septiembre, pp. 344-356.

LiESSE, André (1888): «Comptes rendus», Journal des Économistes, vol. 42, núm. 5, mayo, pp. 304-306.

MANGOLDT, Hans von (1863): Grundriss der Volkswirthschaftslehre, Stuttgart, Verlag von J. Engelhorn.

MARSHALL, Alfred (1873): «Graphic representation by aid of a series of Hyperbolas of some Economic Problems having reference to Monopolies», Proceeding of the Cambridge Philosophical Society, vol. 2, octubre 20, pp. 318-319. Reimpreso en Whitaker (1975, vol. 2, pp. 284-285).

- (1876): «Mr. Mill's Theory of Value», Fortnightly Review, vol. XIX (CXII), abril, pp. 591-602. Reimpreso en Pigou (1966, pp. 119-133).

- (1885): «On the Graphic Method of Statistics», Joumal of the Royal Statistical Society (Jubilee volume), junio, pp. 251-260. Reimpreso en Pigou (1966, pp. 175-187).

- (1898): «Distribution and Exchange», Economic Journal, vol. 8, núm. 29, pp. 37-59.

- (1961): Principles of Economics, Gullebaun, C. W. (ed.), Londres, Macmillan and Co., 2 vols.

MIROWSKI, Philip (1990): «Smooth operator: how Marshall's demand and supply curves made neoclassicism safe for public consumption but unfit for science», en McWILliams Tullberg, Rita (ed.): Alfred Marsball in Retrospect, Aldershot, Edward Elgar, pp. 61-90.

Mises, Ludwig von (1960): La acción bumana, Valencia, Fundación Ignacio Villalonga, vol. 1. Versión castellana de Human Action, London, William Hodge and Co., 1949.

PARKIN, Michael (1990): Economics, Nueva York, Addison-Wesley Publishing.

PARKIN, Michael, y KING, David (1995): Economics, Nueva York, Addison-Wesley Publishsing.

Pigou, Arthur Cecil (ed.) ([1925] 1966): Memorials of Alfred Marshall, Nueva York, Augustus M. Kelley.

PoPEscu, Oreste (1964): Introducción a la Ciencia Económica Contemporánea, Barcelona, Ediciones Ariel.

Pribram, Karl (1934): «Rau, Karl Heinrich», en Seligman, Edwin R. A. (ed.): Encyclopaedia of the Social Sciences, vol. 13, New York, The Macmillan Co., p. 122.

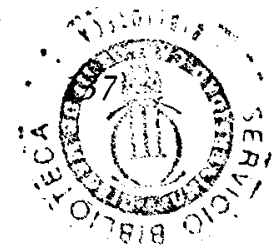


Quételet, Adolph (1846): Lettres à son A. R. le duc régnant de Saxe-Cobourg et Gotha sur la théorie des probabilités appliquée aux sciences morales et politiques, Bruxelles, M. Hayez.

RASHID, Salim (1977): «William Whewell and Early Mathematical Economics», The Manchester Scbool of Economics and Social Studies, vol. XLV, núm. 4, pp. 381-391.

RatrI, Anna María (1935): «Rau, Karl Heinrich», en Enciclopedia Italiana di Scienze, Lettere ed Arti, vol. XVIII, Roma, Istituto della Enciclopedia Italiana, p. 864

RAU, Karl Heinrich (1841a): «Économie politique» (communication du M. Quételet), Bulletin de l'Académie Royale des Sciences et Belles-Lettres de Bruxelles, tome VIII, núm. 9, pp. 148-152.

- (1841b): Lebrbuch der politichen Oekonomie, Heidelberg, Akadem: Verlagshandlung von C. F. Winter [ediciones: $1 .^{\mathrm{a}}(1826), 2 .^{\mathrm{a}}(1833), 3 .^{\mathrm{a}}(1837), 4 .^{\mathrm{a}}$ (1841), $5 .^{a}(1847), 6 .^{a}(1855), 7 .^{a}(1863)$ y $\left.8 .^{a}(1868)\right]$.

- (1876): Allgemeine oder theoretische Volkswirtbschaftslebere (WAGNER, Adolph, y NASSE, Erwin, ed.), Leipzig und Heidelberg, C. F. Winter'sche Verlagshandlung.

- (1968): «Extract from a Letter», en BAUMOL, William J., y GoldFELD, Stephen M. (ed.): Precursors in Matbematical Economics: An Antbology, London, The London School of Economics and Political Science, Aldwych, pp. 181-183.

ReckTENWald, H. C. (1987): «Rau, Karl Heinrich», en Eatwell, John; Milgate, Murray, y Newman, Peter (eds.): The New Palgrave: A Dictionary of Economics, vol. 4, London, The Macmillan Press Ltd., p. 96.

Rodríguez Braun, Carlos (1995): «Las curvas de oferta y demanda de Fleeming Jenkin», Revista de Historia Económica, vol. 12, núm. 2, pp. 311-327.

Roscher, Wilhelm G. (1854): Die Grundlagen der Nationalökonomie, Stuttgart und Tübingen, J. G. Cotta'scher Verlag.

SCHNEIDER, Erich (1960): «Hans von Mangoldt on Price Theory: A Contribution to the History of Mathematical Economics», Econometrica, vol. 28, núm. 2, abril, pp. 380-392.

Schumpeter, Joseph A. (1971): Historia del Análisis Económico, Barcelona, Ediciones Ariel. Traducción castellana de History of Economic Analysis, Oxford, Oxford University Press, 1954.

SEligmaN, Edwin Robert A. (1892): «On the Shifting and Incidence of Taxation», Publications of the American Economic Association, vol. VII, núms. 2 y 3, marzo y mayo, pp. 1-191.

SINEWE, Klaus (1965): Karl Heinrich Rau: Persönlicbkeit und wissenschaftliche. Leistung in moderner Sicht, Inaugural-Dissertation, Fakultät der Friedrich-Alexander-Universität Erlangen-Nürnberg.

Stigler, George J. (1990): «The Place of Marshall's Principles in the Development of Economics», en WHITAKER, John K. (ed.): Centenary Essays on Alfred Marsball, Cambridge, Cambridge University Press, pp. 1-13.

- (1992): Memorias de un economista, Madrid, Espasa-Calpe, S. A. Versión castellana de Memoirs of an unregulated economist, New York, Basic Book, Inc., 1988.

STIGLER, Stephen M. (1980): «Stigler's law of eponymy», Transactions of the New York Academy of Sciences, Serie 2, vol. 39, pp. 147-157. 
STORCH, Heinrich (1820): Handbuch der Nationalwirtbschaftslebre, Hamburg, bei Perthes und Besser, 3 vols.

STREISSLER, Erich W. (1990): «Menger, Böhm-Bawerk, and Wieser: The Origins of the Austrian School», en Hennings, K., y Samuels, W. (eds.): Neoclassical Economics Theory, 1870 to 1930, Boston, Kluwer Academic Publisher, pp. 151-189.

Theocharis, Reghinos D. (1983): Early Developments in Matbematical Economics, London, Macmillan \& Co. Ltd.

- (1993): The Development of Mathematical Economics. The Years of Transition: From Coumot to Jevons, London, Macmillan Press, Ltd.

TrIBE, Keith (1988): Governing economy. The Reformation of German Economic Discourse 1750-1840, Cambridge, Cambridge University Press.

VÁzQUEZ, Andrés (1995): «Marshall and the Mathematization of Economics», Journal of the History of Economic Thought, vol. 17, núm. 2, Fall, pp. 247-265.

- (1997): «The Awareness of Cournot's Recherches among Early British Economists», en SAMUELS, Warren J. y BiDdLE, Jeff E. (ed.): Research in the History of Economic Thought and Methodology, vol. 15, London, JAI Press Inc., pp. $115-137$.

WELLENS-De DONDER, Liliane (1966): Inventaire de la correspondence d'Adolphe Quételet déposée à l'Académie royale de Belgique, Bruxelles, Palais des Académies, coll. $8 .^{\circ}$, t. XXXVII, núm. 1796.

WHITAKER, John K. (ed.) (1975): The Early Economic Writings of Alfred Marshall, 1867-1890, Londres, Macmillan Press Ltd., 2 vols.

- (1996): The Correspondence of Alfred Marshall, Economist, Cambridge, Cambridge University Press, 3 vols.

WolowskI, Louis F. (1857), «Préface. De l'application de la méthode historique a l'étude de l'économie politique», en RosCHer, Wilhelm, Principes d'Économie Politique, Paris, Librairie de Guillaumin et Cie., pp. IX-LXXIII.

WRIGHT, Harold (1927): «Obituary of Frank Lavington», Economic Journal, vol. 37 , núm. 2, septiembre, pp. 503-504. 